\title{
Right ventricular stress-induced perfusion defects and late gadolinium enhancement in coronary artery disease
}

\author{
Michael W Milks', Bharathi Upadhya, Gregory Hundley, R Brandon Stacey \\ From 17th Annual SCMR Scientific Sessions \\ New Orleans, LA, USA. 16-19 January 2014
}

\section{Background}

Due to relatively thin walls, assessment of right ventricular (RV) perfusion defects has remained challenging during vasodilator stress perfusion with cardiovascular magnetic resonance (CMR). Previously, RV perfusion defects observed during radionuclide vasodilator stress have been found associated with adverse cardiovascular (CV) prognosis. However, to date, few data are available regarding the interpretation of RV perfusion defects during vasodilator stress and late gadolinium enhanced CMR.

\section{Methods}

Among 61 individuals aged $59 \pm 11.8$ years, (10\% AfricanAmerican, 47\% women, $81 \%$ hypertensive, 39\% diabetic, and $76 \%$ hyperlipidemic) who underwent cardiac MRI adenosine stress testing prior to cardiac catheterization, we assessed coronary artery stenoses, mortality (assessed by chart review and the social security death index) and the presence of both stress and rest perfusion defects as well as the presence of late gadolinium enhancement by personnel blinded to each aspect of the study. Adjusting for age, race, and gender, a logistic regression model was used to describe the potential association between significant (70\% or greater) coronary stenoses and RV perfusion defects. Adjusting for the same covariates, a Cox proportional hazard model was used to describe the potential association between mortality and the presence of RV late gadolinium enhancement (RVLGE).

\section{Results}

Of the 61 cases, $26 \%(\mathrm{n}=16)$ had no obstructive disease, $30 \%(\mathrm{n}=18)$ had single vessel disease, $21 \%(\mathrm{n}=13)$ had

\footnotetext{
Internal Medicine - Cardiology, Wake Forest Baptist Health, Winston Salem,
} North Carolina, USA

(C) 2014 Milks et al.; licensee BioMed Central Ltd. This is an Open Access article distributed under the terms of the Creative Commons

double vessel disease, $23 \%(n=13)$ had multi-vessel disease, $36 \%(n=22)$ had proximal LAD disease, 39\% $(n=$ 24) had proximal circumflex disease, and $43 \%(n=26)$ had proximal RCA disease. Right ventricular stressinduced perfusion defects were positively associated with proximal RCA and LAD stenoses $(\mathrm{p}<0.01)$. There was a trend toward a significant positive association $(\mathrm{p}=0.10)$ with distal RCA disease, but LCx artery stenosis was associated with not having a stress-induced perfusion defect within the RV myocardium $(p=0.024)$. The

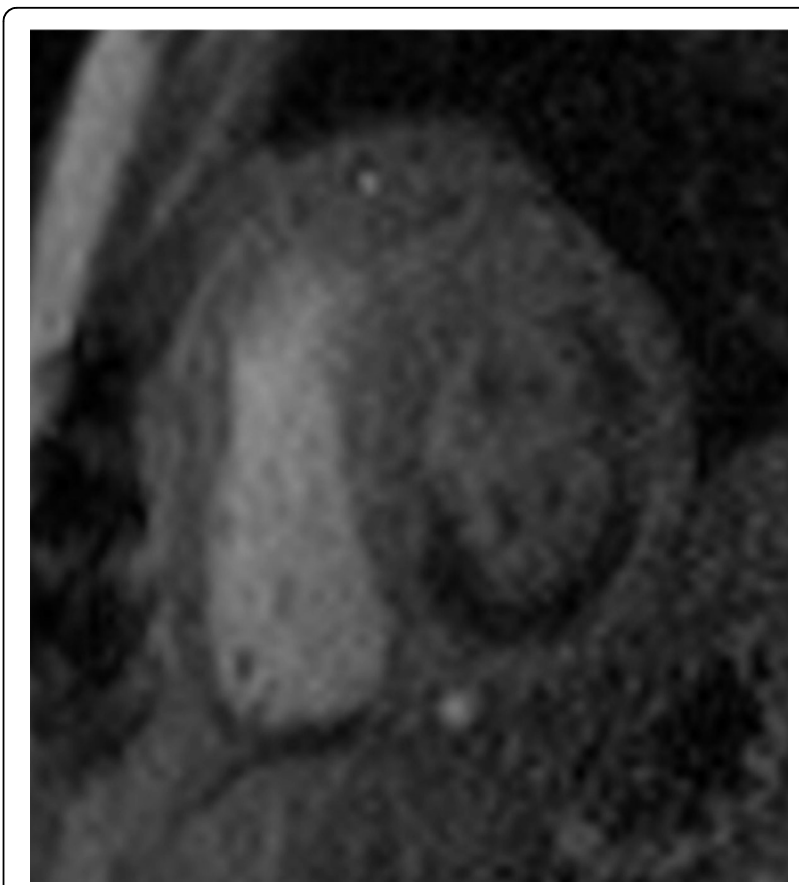

Figure 1 Short axis slice of right ventricular stress-induced perfusion defect. 


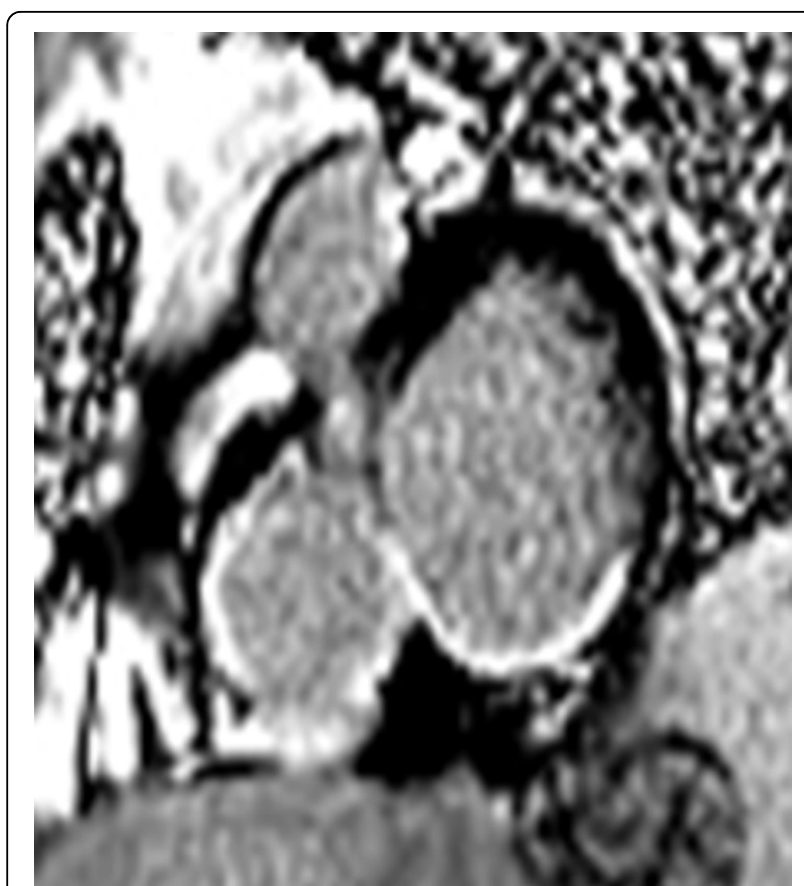

Figure 2 Short axis slice of right ventricular late gadolinium enhancement.

presence of RVLGE was associated with mortality $(\mathrm{p}=$ 0.009), but $77 \%$ of those with RVLGE also had LV late gadolinium enhancement.

\section{Conclusions}

Proximal RCA and LAD stenoses are positively associated, whereas LCx stenoses are negatively associated, with right ventricular stress-induced perfusion defects identified by cardiac MRI stress testing. Right ventricular late gadolinium enhancement was associated with increased mortality, but further studies will be needed to determine if this is independent of left ventricular late gadolinium enhancement.

\section{Funding}

Only departmental funds were needed.

Published: 16 January 2014

doi:10.1186/1532-429X-16-S1-P210

Cite this article as: Milks et al:: Right ventricular stress-induced perfusion defects and late gadolinium enhancement in coronary artery disease. Journal of Cardiovascular Magnetic Resonance 2014 16(Suppl 1):P210.
Submit your next manuscript to BioMed Central and take full advantage of:

- Convenient online submission

- Thorough peer review

- No space constraints or color figure charges

- Immediate publication on acceptance

- Inclusion in PubMed, CAS, Scopus and Google Scholar

- Research which is freely available for redistribution

Submit your manuscript at www.biomedcentral.com/submit
C Biomed Central 